\title{
Implementing Intelligence-Led Policing: An Application of Loose-Coupling Theory
}

\author{
Jeremy G. Carter, Ph.D. \\ Assistant Professor \\ School of Public and Environmental Affairs \\ Indiana University - Purdue University Indianapolis \\ 801 W. Michigan Street, BS 4081 \\ Indianapolis, IN 46202 \\ carterjg@iupui.edu / P: (317) 274-4170 \\ Scott W. Phillips \\ Associate Professor \\ Criminal Justice Department \\ SUNY - Buffalo State \\ Buffalo, New York 14222 \\ S. Marlon Gayadeen \\ Assistant Professor \\ Criminal Justice Department \\ SUNY - Buffalo State \\ Buffalo, New York 14222
}

\begin{abstract}
Purpose: This research is intended to inform a knowledge gap in the literature and present the first national findings related to intelligence-led policing adoption among state and local agencies. Specific practices are identified to inform scholars and practitioners regarding intelligence-led policing behaviors. Methods: Original survey research from a federally-funded project is gleaned to explore intelligence-led policing adoption through a loose-coupling theoretical perspective. Negative binomial and logistic regression models are employed to identify predictive relationships.

Results: Agencies nationwide appear to be closely following the National Criminal Intelligence Sharing Plan recommendations to enhance information sharing. Consistent with the Department of Homeland Security's Target Capabilities List is also observed. Agency size appears to have a significant effect on key organizational information sharing behaviors. The findings are tempered due to limitations in the research design.

Conclusions: Local agencies appear to be tightly-coupled with the recommendations put forth in the National Criminal Intelligence Sharing Plan in their efforts to adopt intelligence-led policing. Agency size appears to enhance adoption across most dependent metrics. This research progresses the limited evidence base and progress regarding this emerging policing philosophy.
\end{abstract}

Keywords: Intelligence-led policing; Information sharing; Change; Coupling; Homeland security

This is the author's manuscript of the article published in final edited form as:

Carter, J. G., Phillips, S. W., \& Gayadeen, S. M. (2014). Implementing Intelligence-Led

Policing: An Application of Loose-Coupling Theory. Journal of Criminal Justice, 42(6), 433-

442. Available from: http://dx.doi.org/10.1016/j.jcrimjus.2014.08.002 
Highlights:

- National data of local law enforcement agencies is utilized.

- Local agencies appear to be closely following federal recommendations for ILP.

- Agencies appear to model their ILP capacity after the DHS target capabilities list.

- Larger agencies have more relationships with organizations and create more products.

- Training specific to ILP enhances the likelihood of adoption.

\section{Citation:}

Carter, J. G., Phillips, S. W. \& Gayadeen, S. M. (2014). Implementing intelligence-led policing: An application of loose-coupling theory. Journal of Criminal Justice, 42(6), 433-442. 


\section{Implementing Intelligence-Led Policing: An Application of Loose-Coupling Theory}

\section{Introduction}

In the 1970s, the Kansas City Preventative Patrol Experiment exposed the limitations of the patrol as an effective method for the police to deal with crime. Since then, police agencies in the United States experimented with several different programs and philosophies intended to improve their effectiveness. In particular, team policing, community policing, problem oriented policing, and Compstat were intended to reduce the police reliance on patrol and responding to calls for service (Phillips, 2012). Each of these innovations expected law enforcement to approach crime reduction through analysis, using the public in a supportive and collaborative

role. This new vista on crime fighting would require a substantive shift in thinking and behavior if the police were to be more effective in reducing and solving crime. Empirical evidence suggests, however, that the features of team policing, community policing, problem oriented policing, and Compstat were not properly implemented (see Dabney, 2010; Eck \& Spelman, 1993; Maguire, 1997; Sherman et al., 1973).

It has been argued that programs are enacted but often encounter problems at the implementation stage (Pressman \& Waldavsky, 1984). Implementation is frequently a complex process because there are often several layers to negotiate (Nakamura \& Smallwood, 1980). For example, organizations may have several different levels and communications channels, complicating the implementation process. Williams (1982), in his research on legislation, argued that at least three levels are involved in the implementation process. The executive-level develops the law, the agency-level applies the law, and the street-level enforces, or implements the law. The gap between the layers often results in disagreement among the actors at the 
various levels, regarding the goal of their particular behavior in relation to the law or program. Feeley (1983) describe this as a "leakage of authority.” For example, when legislatures enacted "mandatory arrest" laws to address domestic violence, the goal at the executive-level was to deter future offenses by making arrest easier for police officers. The goal of street-level officers, however, was not necessarily deterrence. Their focus was to immediately resolve the situation, unlike executives that were procuring a deterrence effect (Phillips, 2008).

This research fills a gap in understanding organizational implementation, by studying the use of intelligence-led policing (ILP); a recently developed approach intended to improve police effectiveness through information sharing and data analysis (Carter \& Carter 2009a). Implementing ILP requires police agencies to shift away from the traditional practices of routine patrol and responding to calls for service (Ratcliffe, 2008). This study is grounded within a loose coupling theoretical framework, which argues there is a gap between what an organization is expected to do and what is actually being done (Hallet, 2010). The implementation of ILP is examined by identifying aspects representative of police agency behavior that may contribute to the connection, or disconnection, between what police are expected to do and what is actually being done with respect to ILP. From a practical perspective, if there are common factors that hinder or enhance the implementation of ILP, police agencies may possibly improve their efforts to utilize this emerging approach. With respect to research, scholars seeking to advance the knowledge base of contemporary policing and intelligence will have an exploratory evidence base to inform their designs. 


\section{Loose Coupling Theory}

In the 1970s, Meyer and Rowan (1977) developed institutional theory (also known as neo-institutionalism) to examine the behavior of organizations. These scholars reported that organizations prescribe to symbolic myths and ceremonies in order to achieve field legitimacy. With field legitimacy, organizations receive resources, thereby procuring a level of stability in the occupational field (Crank \& Langworthy, 1992). The cognitive methods to field acceptance are anchored in isomorphism or homogeneous practices. As DiMaggio and Powell (1983, p. 149) claimed isomorphism is a method "that forces one" organization into "the same set of environment conditions” as others within field. The three forms of isomorphism are coercive, mimetic and normative. Coercive isomorphism is institutional practices that are imposed by regulatory bodies (e.g. government). Mimetic are successful practices that are copied "from one another," while normative isomorphism are directives from professionals that align organizational practices (Deflem, 2008, p. 150). Loose coupling occurs when prescribed organizational practices are not followed because of internal organizational contingencies (Edelman, 1992; Meyer \& Rowan, 1977).

Loose coupling theory suggests that organizations are split into two levels, allowing them to behave rationally at one level while responding to uncertainty at another (Thompson, 1967). These groups are the superordinate or dominant coalition, and the subordinate or work process group (Ingersoll, 1993; Weick, 1969, 1976, 1982). The former contain leaders or supervisors within an organization that are charged with maintaining institutional legitimacy (Meyer \& Rowan, 1977). The superordinate level preserves legitimacy by developing institutional policies and practices that signal to the external environment they are aligned with field performance. That is, the superordinate level performs in a way satisfying the expectations of the external 
environment. The external environment includes political counterparts, groups who can apply pressure on an agency, and the media. The subordinate or work process group is comprised of institutional actors (e.g. street-level workers) that are expected to follow the dominant coalition's prescription for the agency. These workers, however, exist in an environment where their behavior may require modifications from what is expected. Thus, institutional actors retain a level of independence in how they perform their duties. In short, the dominant coalition prescribes or enacts institutional practices, while the work process group is expected to subscribe to or implement those desired practices. The fact that the superordinate and subordinate levels are linked is found in the word "coupled," while the fact these elements have a degree of independence from each other is found by the word "loosely" (Orton \& Weick, 1990).

Loose coupling is a suitable theory to predict or explain the gap between the administrative and street-level layers of an organization (Feeley, 1983; Williams, 1982). Loose coupling suggests that both groups do not always work in tandem (Weick, 1969, 1976, 1982; Ingersoll, 1993). The disconnection or "slippage" between the desired outcomes by the dominant coalition and the actual practice by the work process group is grounded in the reality of the organization or profession (Lipsky, 1980). As Stojkovic, Kalinich, and Klofas (2003) might posit, the discretion of street-level workers cannot be fully accounted for. Specifically, engaging diverse populations requires flexibility in street-level authority in order to adhere to public needs (Stojkovic, et al., 2003).

\section{Loose Coupling and Policing}

Loose coupling theory has been a developing area of policing scholarship. Central to policing and loose coupling research are observations on organization size; specifically, 
disconnect between the desires of the dominant coalition and practices of the work process group. Policing scholarship suggests this slippage between both groups directly corresponds to agency size. Mastrofski and his colleagues (1987) reported that administrators for large organizations do not closely monitor officers, as that they tend to be more concerned with appeasing the external environment. This, then, provides officers in large agencies a greater degree of discretion when compared to their counterparts in smaller agencies. Mastrofski et al. (1987) supported their claim by reporting that officers in smaller agencies were likely to arrest all drunk-driving offenders, while officers in larger agencies would arrest $50 \%$ to $60 \%$ of violators.

Other scholars contend there are additional considerations beyond agency size that explain the loose coupling between the dominant coalition and work process group in police organizations. Brown (1981) found that officers in smaller agencies in California exercised more discretion than officers in larger agencies, such as the Los Angeles Police Department (LAPD). Brown (1981) suggested that small agencies, given their high-visibility, would need to exercise discretion to minimize public concerns. Phillips' (2008) research on domestic violence and mandatory arrests reported that agency size was not correlated to police practices. Rather, the likelihood of arrests in domestic violence incidents is best explained by the situational variables in a domestic violence incident (i.e., victim injury, the existence of an order of protection, and the cooperation of the offender) (Phillips, 2008).

\section{Intelligence-Led Policing (ILP)}

For the past decade, American law enforcement has faced implementation and operational challenges of adopting an emerging policing philosophy known as ILP (Carter \& 
Carter, 2009a; Crank et al., 2010; Darroch \& Mazerolle, 2013). This ambiguity and implementation fidelity mirrors the law enforcement experience with community policing throughout the past 30 years. This new philosophy has been widely accepted with little exploration. Anecdotal evidence suggests four important factors for this occurring. First, after September 11, 2001, there was a strong desire on behalf of state and local agencies to "do something” in order to prevent a similar attack from occurring again. Second, there was a strong, unified message from police leaders and the U.S. Department of Justice's Global Intelligence Working Group that it was necessary to implement ILP to protect communities consistent with national standards. Third, in the years since September 11, 2001, agencies saw what they believed to be success in combating crime beyond terrorism by utilizing the intelligence-led approach (Bureau of Justice Assistance, 2010). Lastly, the application of ILP is believed to be an effective approach to target and reduce violent crime in urban areas (Bureau of Justice Assistance, 2010).

Similar to the evolution of community policing, ILP seeks to reform existing police practices to improve the efficiency and effectiveness of existing processes. While community policing largely relied on a re-shaping of existing resources, ILP requires some additional resources in the form of an analytic capability. This capability can be created within an agency by hiring an intelligence analyst or by relying upon the analytic capability of fusion centers that are designed to support and facilitate information sharing for law enforcement (Carter and Carter, 2009b). Despite this integrated analytic function, ILP mirrors the transformation towards community policing wherein agencies were not expected to overhaul their organization. ILP is built upon best practices established by community policing while emphasizing an integrated information, or evidence-based, decision making to help inform strategic resource allocations or 
inform patrol officers of emerging trends and tactics in jurisdictional crime. When summarizing the change experienced by police agencies with regard to ILP, Wood and Shearing (2007, p. 55) explained "[ILP] does not re-imagine the police role so much as it re-imagines how the police can be smarter in the application of their unique authority and capacities.”

Ratcliffe (2008) describes ILP as a comprehensive adjustment of organizational functions that align tasks and operations with intelligence and analytic capabilities. In addition, he notes several specific areas where police agencies engaged in ILP will divert from practices typically found within law enforcement's purview. To begin with, personnel - specifically those personnel who are responsible for the intelligence function within their agency - must be formally trained to comprehend the function of intelligence and information sharing. Next, there must be regular channels to communicate intelligence to personnel making decisions. These strategic and tactical decisions should be driven by intelligence products that result from a formal analytic process. These products should be diverse to best inform the range of complex activities law enforcement is responsible for delivering. Lastly, there must be changes to organizational structure and accountability to ensure intelligence-related functions are resourced and a priority to the agency (Carter \& Carter, 2009a; Ratcliffe, 2008).

Beyond the aforementioned internal organizational changes, scholars contend that ILP (as practiced in the United States vs the United Kingdom) should employ community policing principles (Carter \& Carter, 2009a; Chappell \& Gibson, 2009; Innes, 2006). Perhaps the key component gleaned from community policing is the emphasis on two-way information sharing with the public. Such an approach should not be limited to relationships between police and the communities they serve, but also among law enforcement agencies themselves. As a result of the highly fragmented structure of American law enforcement, many geographic areas contain 
multiple police authority jurisdictions - such as county sheriff, different municipalities, state police, and possible township or university police as well. Despite sharing the same geographic proximity, anecdotal evidence suggests these agencies rarely communicated relevant information across one another (Carter, 2009). In wake of the communication failures leading up to September 11, 2001, the need for law enforcement to develop cooperative relationships with agencies within and outside of their own jurisdiction has been paramount. These relationships should be reciprocal in nature where agencies proactively and reactively share information. Exploratory research in this area indicates such relationships exist, but are being under-utilized for enhancing information sharing (Carter, 2014).

The difficulty associated with implementing ILP has been a lack of specific guidance. More often than not, general guides or standards are disseminated by the federal government to communicate an initiative. These documents call for the law enforcement community to do something, but provide little tangible guidance. One such example of this is the Department of Homeland Security's Target Capabilities List (TCL) that identifies and emphasizes the role of intelligence and information sharing for local law enforcement beyond a focus that has predominantly been terrorism-centric. The TCL "provides a guide for developing a national network of capabilities that will be available when and where they are needed to prevent, protect against, respond to, and recover from major events” (U.S. Department of Homeland Security, 2007, p.5). While certainly important to the greater intelligence landscape, the TCL is difficult for the average municipal agency in the U.S. to translate into practice.

To date, there have been two predominant sources of information for law enforcement to reference when adopting an intelligence-led approach into the daily operations of their department. First, the National Criminal Intelligence Sharing Plan (NCISP) was published in 
coordination with the Global Intelligence Working Group and the U.S. Department of Justice. These entities represent the federal perspective of ILP, as it should be practiced by state and local agencies. From a loose coupling perspective, the NCISP represents the characteristics to which state and local law enforcement should adhere to, for successful ILP. Second, a comprehensive guide was funded by the Office of Community Oriented Policing Services (COPS) and written by David L. Carter (2009). The perspectives of this guide are largely consistent with the recommendations put forth by the NCISP. This COPS guide has been widely utilized by law enforcement practitioners and serves as a comprehensive source for a range of law enforcement intelligence topics. Beyond simply information sharing and ILP, this guide examines civil rights and privacy, public-private partnerships, fusion centers, suspicious activity, and open source information. This research utilizes the NCISP as representative of the coupling framework between federal government and state and local law enforcement. The authors came to this conclusion for two reasons. The NCISP is written and published directly from the federal government and Carter's (2009) guide is largely based on the recommendations put forth by the NCISP.

\section{National Criminal Intelligence Sharing Plan}

In March 2002, law enforcement executives from across the country gathered at the International Association of Chiefs of Police (IACP) Criminal Intelligence Sharing Summit to articulate a proposal for an intelligence sharing plan that aligned with then-President Bush's homeland security initiative. Participants of this summit envisioned law enforcement agencies at all levels of government engaging to coordinate, collect, analyze, and appropriately disseminate criminal intelligence across the United States (The Police Chief, 2003). Consistent with the 
American experience of community policing, ILP is an evolving concept (Ratcliffe, 2008; Schaible \& Sheffield, 2013) that is unique to each agency (Carter and Carter, 2009a). To date, state and local law enforcement have relied upon the National Criminal Intelligence Sharing Plan (NCISP) as a guiding policy through which ILP is intended to operate in the United States. Though the NCISP is the foundation for ILP, it is important to note that the two are not synonymous. The NCISP provides a framework through which ILP can be operationally applied to law enforcement agencies (Carter \& Carter, 2009a). It is a recommendation guide-post and source of standards to which law enforcement should map their intelligence functions.

The NCISP serves as a tool through which state and local law enforcement can translate the greater notion of "law enforcement intelligence" into an operational and strategic program of practice. This greater notion of law enforcement intelligence is, in its most simple form, a general term that applies to the philosophy and apparatus of information sharing strictly among law enforcement (primarily state, local, and tribal) organizations (Carter, 2009). This general term also signifies the contrast of intelligence as it applies to local law enforcement versus national security organizations. A discussion of these differences is beyond the scope of the current research; it is sufficient to say stark differences exist between law enforcement intelligence and national security intelligence with regard to strategic focus, objectives, and legalities.

\section{Current Research}

At present, the literature suffers from a lack of empirical research within the area of law enforcement intelligence and information sharing. This shortcoming is a result of unwillingness on behalf of law enforcement agencies to provide to researchers data and information pertaining 
to sensitive operations such as intelligence. Moreover, there has been a lack of appropriate theory application to examine intelligence-led policing. The present research seeks to inform these shortcomings by utilizing loose coupling theory and data from a national sample of law enforcement agencies and their intelligence practices. From the outset it is important to acknowledge that the present research has limited generalizability due to a small sample of agencies relative to the number of agencies nationwide. Despite this limitation to external validity, the constructs examined to explore intelligence practices and loose coupling theory within the sample agencies are uniquely valid to the greater research question and literature given the intelligence-specific nature of the survey items and respondents’ knowledge. Further detail regarding the survey and study methodology will be discussed in the section to follow.

Loose coupling theory posits that a dominant coalition will develop and influence a desired change. The dominant coalition in this study is the U.S. Department of Justice, for several reasons. First, the USDOJ published the National Criminal Intelligence Sharing Plan (NCISP), which recommends all police agencies develop their intelligence capability (Global Intelligence Working Group, 2003). Second, in 2002, the COPS Office funded an "Intelligence Summit," which was hosted by the International Association of Chiefs of Police. "At this summit, law enforcement professionals expressed frustration in the lack of guidance from the government as to how intelligence-led policing should be defined and put into practice” (Carter \& Phillips, 2013, p. 3). These features of the USDOJ fit within the dominant coalition's duties to develop policies to achieve goals (Stojkovic, et al., 2003). Individual police agencies will be considered the work process group. Police agencies are expected to implement the recommendations of the dominant coalition; thus local police agencies are expected to implement operational aspects of ILP. 
This research examines several dependent measures that indicate an active ILP approach in policing. Regression analyses are employed to examine the predictive impact of several independent variables on the implementation of ILP. Because this study frames loose coupling differently than past studies (i.e., inter-organizational vs. intra-organizational), it is difficult to articulate specific hypothesize. For example, others found loose coupling within larger police agencies (Mastrofski, et al., 1987). It might be expected here, however, that larger police agencies would be tightly coupled with the dominant coalition because larger agencies had access to knowledge and resources to adequately implement aspects of ILP. Further discussion of the findings as applied to theory and practice are presented.

\section{Measures}

Data

Data were gleaned from a larger project funded by the National Institute of Justice ${ }^{1}$ which conducted a national survey of law enforcement intelligence practices of different key personnel. This purposive sample of law enforcement personnel included individuals who had attended a national training program funded by the Department of Homeland Security. This sampling strategy was primarily chosen for multiple reasons. By attending this training, these personnel were identified by their respective agency as a representative of the intelligence function within the agency. These persons are most likely to be the personnel who have direct knowledge and a working understanding of key issues related to intelligence and information sharing - thus they are most knowledgeable about the practices of interest. This approach has been utilized in police research focused on specialty personnel when examining issues such as police assigned to cybercrime (Bossler \& Holt, 2012) and policing sex workers (Simic et al.,

\footnotetext{
${ }^{1}$ Grant number 2008-IJ-CX-0007. National Institute of Justice, U.S. Department of Justice.
} 
2006). Empirical research exploring law enforcement intelligence issues has been severely hampered by a lack of access to, and unwillingness to participate by, intelligence personnel within agencies (see Chermak et al. 2013). Moreover, ideal surveying methods - such as random sampling - are not feasible given the fidelity of intelligence practices nationwide. Not every law enforcement agency in the country is actively engaged in information sharing and intelligence practices (Carter \& Phillips 2013), thus a targeted sample is required.

\section{Survey of Key Personnel}

The survey was administered using a web-based software program and training participants' email addresses. A single individual working within the intelligence function responded to the survey on behalf of the agency. Throughout the sampling process, the sampling frame was corrected by removing individuals who could not be contacted or who declined to participate. Invitation e-mails were sent to a sample of 967 agencies to participate in the study. A total of 272 state, local, and tribal law enforcement agencies are included in the sample. The response rate for the present study is $28 \%(n=272 / 967)$. Such a response rate is not surprising, given online-based surveys yield lower response rates than traditional mail or in-person surveys (Shih \& Fan, 2009), that cross-sectional response rates in social sciences are declining (Brick \& Williams, 2013), and the exploratory nature of the research within an area of law enforcement commonly believed to be a difficult one to sample (Chermak et al., 2013). Despite the less than ideal response rate, the sample includes agencies from small, medium, and large municipalities, county sheriffs, and state police. Moreover, 41 states (including the District of Columbia) with geographic distribution across the five regions of the U.S. are represented in the sample. 
To explore why the response rate was not higher, follow-up telephone interviews were conducted with 100 randomly selected participants from the sample. Among the key reasons that were consistently reported for not responding were a change in job responsibilities, survey length (more than 100 questions), and sensitivity to sharing information related to intelligence practices. Examining the non-response bias was not possible and given there is no national data related to law enforcement intelligence for comparison, the results to follow should be interpreted with caution.

The present study provides unique value due to a significant empirical gap in the knowledge base of ILP, especially at the national-level. As a result this study serves as one of the few empirical explorations into the factors associated with the ILP philosophy. Table 1 displays descriptive information for the agencies and respondents represented in the current study. The median agency size is 276 total sworn and non-sworn personnel and most agencies included in the sample were located in the Midwest region of the United States, followed closely by the Southeast and Northwest. Respondents are mostly investigators and administrators who have been employed by their agency for more than 15 years.

[ Table 1 approximately here ]

\section{Measures}

Similar to community policing, appropriate dependent variables can vary based on implementation or practice as there is no specific operationalization of community policing or ILP. Because implementation, especially nationwide, can be examined across varying 
applications of the philosophy and unique agency characteristics, the present research will examine different dependent variables as indicators of implementation. Also, a variety of independent variables is included to identify factors that may contribute to, or resist, program implementation. Appendix A includes a list of each dependent and independent measure, how the item was presented on the survey, response options for the item, and measure construction information if applicable.

One of the difficulties associated with this research is parsing out the differences between dependent and explanatory variables. This issue pertains to the use of intelligence-related explanatory variables to draw inferences regarding ILP dependent variables. As the majority of police organizational change literature has utilized traditional measures of structure and complexity to explain the adoption of change (see Maguire, 1997; Maguire et al., 2003; Morabito, 2010), ILP requires a more nuanced set of variables to target specific practices. As mentioned previously, ILP is viewed as a strategic modification to existing policing practices. Agencies do not "change" as much as they "tweak" what they are doing. The emphasis is on the utilization of intelligence and the sharing of information. Thus, targeted measures that represent specific functions within an agency are necessary to inform the desired outcome.

For example, one of the common measures of organizational control (within the complexity construct to adopt change) is formalization - the extent to which agencies have formal policies. If a general approach were taken, an agency may have a high-degree of formalization due to their written policies regarding use of force, domestic violence, vehicle pursuit, and so forth, but could be missing a specific policy that guide their intelligence function. Given the more-formal and civilly-sensitive nature of intelligence in law enforcement, this 
absence of an intelligence-specific policy is noteworthy and should be captured - as opposed to a general scale of agency formalization.

In an attempt to capture differences between factors believed to be dependent versus explanatory, exploratory factors analysis was employed to identify a latent construct associated with the dependent variables and independent variables to be described below. These variables were identified primarily on theory and one of the author's professional experiences training law enforcement on the practice of ILP. Theoretically speaking, the dependent measures represent a general latent construct of an observable intelligence output from an organization while independent variables represent structures and process to create the observable output. Factor analysis identified a single latent factor among the six dependent variables (eigenvalue of 3.35) as well as a single latent factor among the nine independent variables (eigenvalue of 4.83). When all fifteen variables are included in the factor analysis, two latent constructs are identified (eigenvalues of 2.38 and 1.52). Though not definitive, this exploratory analysis lends support, outside theory and practice, that the dependent and independent factors utilized in this research are likely representative of different constructs.

\section{Dependent Variables}

Six dependent variables were selected as measures of police agency behavior that would indicate a strong or "tight" association between ILP and the recommendations put forth in the NCISP. First, a scaled variable was created to reflect the variation in analytic products created by an agency. These intelligence products included Bulletins, Risk Assessments, Advisories, Alerts, Warnings, Executive Reports, and Briefings. This variable is representative of an analytic function within the agency as a combination of product types and frequency of creation. 
Agencies that create a greater variation of intelligence products are reflective of engaging in ILP. Second, whether or not information sharing is explicitly rewarded in the agency through formal evaluation. Agencies that reward information sharing demonstrate a commitment to this emerging philosophy. Having this reward function integrated into the formal evaluation process signifies a formal commitment to ILP as opposed to an informal "lip service" that the agency feels information sharing is important. Third, a scale was developed to represent the extent to which an agency has close working relationships with external organizations. The nature of the relationships for this index is specifically for the purpose of sharing information. Working with external organizations to share information is at the heart of ILP. Fourth, the extent to which an agency provides intelligence to external agencies. Related to this variable is the fifth measure, the extent to which an agency receives intelligence from external agencies. This two-way information sharing is an activity measure of ILP inputs and outputs. Lastly, intelligence is formally integrated into the agency's decision making process. This strategic use of intelligence is the operational key to ILP.

\section{Independent Variables}

As mentioned at the onset of this research, institutional theory posits that agencies adopt occupational practices to obtain legitimacy and resources. Dominant coalitions with regulatory authority prescribe templates to subordinate bodies, often in the form of manuals, reports, and training. These written prescriptions are tools for agencies to follow, which illustrate their work process alignment in the occupational field. As noted earlier, the NCISP developed by the U.S. Department of Justice is expected to provide a means of diffusing and aligning ILP methods and ideologies across local law enforcement agencies. This normative form of isomorphism guided 
the selection process of independent variables for analysis. Questions were selected based on either of the following contextual-components.

First, at the core of institutional theory, and by extension loose coupling, is the idea of commitment to the organizational field. Words, such as "function" and "align" signal an agency's commitment to field practices. If a survey item had terminology that was aligned with institutional theory and loose coupling ideologies, it was included as an independent variable. For example: “Does your agency’s intelligence function follow the NCISP Recommendations?” Second, survey items that identified acronyms were used in the selection process. These types of items tend to be a form of ritualized vocabulary to demarcate field identity. Moreover, ceremonial practices, including adoption of terminology, denote agency engagement to prescribed functional practices within a field. For instance: "Does your agency align with the DHS Target Capabilities List (TCL)?” As Stinchcombe (1997) might argue, the ritualized vocabulary (e.g. acronyms and institutional terminology) that become part of the ethos of an organization, signals to institutional actors and others important subject matters.

Additional independent variables focused on structural and process aspects of intelligence within agencies. These variables were identified through organizational policing literature as well as one of the author's professional experiences training law enforcement specifically within the area of intelligence. Whether or not an agency has a specific policy in place to guide their intelligence function, had a process in place to share information with the public, required intelligence-specific training, focused on suspicious activity related to all-crimes (rather than just terrorism), the extent to which respondents believed their agency had sufficient staff for their intelligence capability, were consistent with federal privacy guidelines for sharing information, and also audited the intelligence records system were identified as critical components necessary 
to implement ILP. Agency size, as measured using the Federal Bureau of Investigation's Police Employee Data, is included in the models as agency size is believed to influence the extent to which agencies engage in ILP. For purposes of the analytic models, a natural log transformation of agency size was utilized given the skewed distribution of the size data.

As can be seen in Table 2, with respect to the dependent variables, agencies on average create approximately half (16.73) of the intelligence products on a regular basis while an average of 40 percent of agencies formally reward information sharing. Responding agencies had, on average, rather close working relationships with external organizations specifically for information sharing. Agencies indicated, on average, receiving intelligence (14.13) from external organizations slightly more frequently than they provide it (13.80). On average, respondents agree that intelligence is integrated into the decision making process. In regard to independent variables, based on the modal response category, agencies mostly follow the NCISP, somewhat align their intelligence capacity with the TCL, are currently developing an intelligence policy, and do not believe they have sufficient staff for their intelligence function. On average, 44 percent of agencies have a process for sharing information with the public, 75 percent employ an all-crimes approach to suspicious activity reporting, and 51 percent are consistent with federal privacy guidelines.

[ Table 2 approximately here ]

\section{Analytic Strategy}

The present research primarily utilizes negative binomial regression with incident rate ratio coefficients, or exponentiated beta, to explore the count dependent variables. Odds ratios 
are reported to ease interpretation of findings as opposed to drawing inferences from logged counts (i.e., it is difficult to translate a one-unit increase of intelligence practices). Pearson Chi Square goodness-of-fit tests indicate the distribution of the count dependent variables differed significantly from a Poisson distribution, thus the decision to utilize negative binomial models. For the information sharing reward variable, which is dichotomous, logistic regression was employed with odds ratios reported and robust standard errors. Given the exploratory nature of the research, bivariate and multicollinearity diagnostics were conducted and no concerns were identified. Both tolerance and variance inflation factors were well within acceptable levels. Due to space considerations, these results are not presented and can be provided by the authors upon request.

\section{Findings}

To best present the findings, the six dependent measures can be grouped into two general categories. First, findings pertaining to "Intelligence-Led Policing Behaviors" are presented in Table 3 and consist of the scale of analytic products created, if the agency formally integrates intelligence into the decision making process, and whether or not information sharing is formally rewarded in the agency. Second, findings reflective of "Information Sharing Behaviors with External Agencies” are presented in Table 4 and include working relationships with external organizations specifically for sharing information, the frequency at which an agency provides intelligence to external organizations, and the extent to which agencies receive intelligence from external organizations. The findings are insightful.

Intelligence-Led Policing Behaviors 
Table 3 presents the findings related to ILP behaviors. To begin with, the strongest predictor of these three ILP behaviors is the consistency to which agencies follow the recommendations put forth in the NCISP. As agencies follow the NCISP recommendations more closely, they are almost five times more likely to create a variety of intelligence products (4.81) and formally reward information sharing (4.79) while being almost three times as likely to formally integrate intelligence into their decision making process (2.97). This is a welcomed finding as it appears agencies are adhering to the recommendations within the NCISP - an indication of tight-coupling. With respect to indicators of agencies that create a variety of intelligence products, closer alignment with the Department of Homeland Security's Target Capabilities List (1.99) and consistent with privacy guidelines (2.01) double the likelihood of creating more products. Agencies that specifically have an intelligence policy (2.51), as well as larger agencies (3.96), also have a greater likelihood of producing analytic products. This latter finding is likely a function of variance in personnel and task scope commonly found within larger agencies (Maguire et al., 2003). Surprisingly, it appears that agencies that believed they had sufficient staff for their intelligence function was not indicative of creating intelligence products. This is perhaps due to the non-specific nature of the question and future research could consider soliciting information specific to intelligence analyst personnel.

\section{[ Table 3 approximately here ]}

Agencies that formally integrate intelligence into their decision making process believed they had sufficient staff (2.89) for their intelligence function. Agencies that required personnel to receive intelligence-specific training (2.23) were also more likely to utilize intelligence for decision making. Of interest is that it appears having a formal intelligence policy is not an 
indicator of formally integrating intelligence into decision making. This is also true of agencies that formally reward information sharing. It would seem that if an agency formally rewarded personnel for sharing information, via the personnel evaluation process, that agency would have a policy specific to intelligence to guide behaviors and outcomes of personnel. This appears not to be the case and may be more reflective of an informal culture of information sharing as opposed to a systematic process to collect, analyze, and disseminate information. More intuitively, intelligence training (2.97) and processes for sharing information with the public (2.70) were strong indicators of agencies that reward information sharing. Agencies that perceived having a sufficient staff were also more likely to formally reward information sharing.

\section{Information Sharing Behaviors with External Agencies}

Table 4 presents the findings from information sharing behaviors with external agencies. Similar to the previous group of models, agency information sharing behaviors are strongly driven by consistency with the NCISP recommendations. The closer agencies followed the NCISP, they were almost three times more likely to have closer relationships with external agencies (2.91), four times more likely to provide intelligence to external agencies (4.61), and over five times more likely to receive intelligence from external agencies (5.39). However, it appears the strongest indicator of these three behaviors is agency size. Larger agencies demonstrate an increased likelihood of having more working relationships (2.90) and provide intelligence to more external agencies (3.05) more frequently. This finding likely eludes to the greater range of personnel and tasks often associated with larger agencies and is consistent with previous research in multi-agency crime reduction partnerships (Rosenbaum, 2002) and terrorism preparedness (Randol, 2012). Interestingly this finding does not hold true for larger 
agencies receiving intelligence from external agencies. This is likely due to the influence of fusion centers. Agencies of all sizes receive intelligence products from fusion centers (Carter \& Chermak, 2012), however, not all agencies have an intelligence production capability and those that do are typically larger in size. Thus, despite differences in size (and personnel resources), there is likely no discernable difference between intelligence received across different agencies.

\section{[ Table 4 approximately here ]}

Agencies that more tightly coupled with the TCL are also more likely to have working relationships for intelligence (2.96) as well as provide (3.36) and receive (2.01) intelligence. This finding is expected given the focus of the TCL as an "all hazards" threat prevention, mitigation, and response framework. Active communication and close relationships are critical for emergency management and often involve agencies beyond just law enforcement (i.e., fire, emergency medical, transportation, etc.). Though the measurement here is limited to strictly law enforcement, agencies that align with the TCL are expected to have a wide range of relationships.

The final predictor of external relationships for information sharing was the presence of processes to share information with the public (2.19). With regard to providing intelligence to external organizations, requiring personnel to attend intelligence-specific training (2.04) and more frequently auditing the intelligence records system (3.08) are additional predictive factors. Within all of the models tested here, the frequent auditing of intelligence records is only a predictor of providing intelligence to other agencies. This is a welcomed finding and perhaps speaks to the contemporary nature of law enforcement intelligence. As time passed following the September $11^{\text {th }}$ attacks, there has been a shift in concern among citizens from terrorism to the 
possibility of civil rights violations on behalf of law enforcement being overzealous (Carter, 2009). Though this cannot be examined in the current research, in light of this context it seems reasonable to assume that agencies who regularly audit their intelligence records system (to purge information that violates 28 CFR Part 23 laws) are more willing to share their information as they have taken safeguards to ensure the information is lawful.

\section{Conclusion}

This study examined implementation of intelligence-led policing within a loose coupling framework. While the research into ILP is growing (i.e., Carter, 2014; Carter \& Carter, 2009a, 2009b; Carter \& Phillips, 2013, Darroch \& Mazerolle, 2013; McGarrell et al., 2007; Ratcliffe, 2008; Ratcliffe, \& Guidetti, 2008; Schaible \& Sheffield, 2012), there is an absence of scholarship providing science-based insights of how ILP operates within local police agencies as well as the factors associated with its implementation. The findings reported here attempt to fill this void. Though the findings presented here are unique to the literature and provide insights about the adoption of intelligence-led policing, limitations exist.

The data used to measure both dependent and independent variables are the result of a self-response survey where a single individual responded on behalf of his/her agency. While this is a limitation, it has been argued that this approach is necessary due to the complexities and dynamic nature of intelligence within law enforcement agencies and these persons are best positioned to respond to the survey. The results presented should be accepted with caution, due to an inability to detect the nature of the response bias and since there is no national data related to intelligence for comparison. 
Despite this limitation, this research indicates that, as operationalized here, the superordinate and subordinate levels are fairly well connected. Specifically, the NCISP, as articulated by the federal government, represents the superordinate or dominate coalition level that prescribes institutional practices. The local law enforcement agencies represent the subordinate or work process group that is expected to subscribe to or implement the desired practices of the superordinate group. The findings indicate that the ILP activities of local police agencies are fairly well-connected to the behavior they are expected to perform. Adhering to the recommendations of the NCISP illustrates the greatest uniformity with the expected behaviors of creating analytic products, integrating intelligence into the decision making process, and the rewarding of information sharing. These findings are consistent with Ratcliff's (2008) assertion that ILP calls for an adjustment in organizational functions; that strategic and tactical decisions should be related to a formal analytic process. In addition, closely following the NCISP was significantly related to all the information sharing behaviors.

Aspects of field identity, such as acronyms and terminology, also appear related to tight coupling between the behavior that is expected from the dominate coalition and the behavior that is actually performed by the work process group. For example, the use of Department of Homeland Security's Target Capabilities Lists (TCL), while vague in actual guidance for police agencies, is related to the creation of analytic products and all forms of information sharing. It may be that, despite the ambiguity of the TCL, they demonstrate police engagement with ILP; they may have become part of the organizational ethos of police departments, and therefore, important for the agencies to utilize.

The influence of agency size and its relationship to the outcomes measures merits special attention for the current research as well as for the guidance of future research. First, it seems to 
be no surprise that size is related to the creation of analytic products. This may be a simple issue of resources: larger agencies may have a budget that allows greater access to computer and information technology (i.e., records systems and data mining subscriptions) that assist with more sophisticated analyses. Further, larger agencies likely have residual personnel, and assigning a specialized analyst to a unique role may be an easy task. Second, the fact that agency size is not related to decision making is an important finding, suggesting two possible behaviors: All police agencies, regardless of size, use their analytic products as part of their decision making, or police agencies in general do not connect analysis with decision making. Future research will have to untangle this result with more detailed measures that link decision making with ILP products. Larger agencies, however, were significantly associated with working relationships and providing intelligence to external agencies. It seems reasonable to assert that larger agencies are likely surrounded by other "suburban" agencies in a "cosmopolitan network" (Skogan and Hartnett, 2005 p. 402). Thus, larger police agencies may already have a working relationship with a number of surrounding police agencies.

Considerations for future research should include an exploration of appropriate ILP models across varying agency sizes and community compositions. Aside from aforementioned size-related factors, research on homeland security preparedness among local law enforcement has indicated agency size is perhaps not as salient as an agency's geographic proximity to a major urban area (Schafer et al., 2009); the same is likely true for ILP. A comprehensive metric of ILP is needed. Similar to community policing research, scholars should consider developing a scaled index item of intelligence practices. This is made difficult given significant fidelity across agencies and even among scholars. It is believed the present research is a step in this direction 
despite the dependent and independent variables not being originally constructed for purposes of evaluating ILP adoption. 


\section{References}

Bossler, A. M. \& Holt, T. J. (2012). Patrol officers’ perceived role in responding to cybercrime. Policing: an international journal of police strategies \& management, 35(1), 165-181.

Brick, J. M. \& Williams, D. (2013). Explaining rising nonresponse rates in cross-sectional surveys. The ANNALS of the American Academy of Political and Social Science, 645(1), 3659.

Brown, M. K. (1981). Working the Streets: Police Discretion and the Dilemmas of Reform. New York: Russell Sage Foundation.

Bureau of Justice Assistance. (2010). Reducing Crime through Intelligence-Led Policing. Washington, DC: U.S. Department of Justice.

Carter, D. (2009). Law Enforcement Intelligence: A Guide for State, Local, and Tribal Law Enforcement Agencies. (2 ${ }^{\text {nd }}$ ed.). Washington, DC: U.S. Department of Justice.

Carter, D. L. \& Carter, J. G. (2009a). Intelligence-led policing: Conceptual considerations for public policy. Criminal Justice Policy Review, 20(3), 310-325.

Carter, D. L. \& Carter, J. G. (2009b). The intelligence fusion process for state, local and tribal law enforcement. Criminal Justice and Behavior, 36(12), 1323-1339.

Carter, J. G. (2014). Inter-organizational relationships and law enforcement information sharing post-September 11, 2001. Journal of Crime and Justice. Advanced online publication. DOI: 10.1080/0735648X.2014.927786.

Carter, J. G. \& Phillips, S. W. (2013). Forces of organizational change and intelligence-led policing in the USA. Policing and Society. Advanced online publication. DOI: 10.1080/10439463.2013.865738

Carter, J. G. \& Chermak, S. (2012). Evidence-Based Intelligence Practices: Examining the Role of Fusion Centers as a Critical Source of Information. In C. Lum \& L. Kennedy (Eds.) Evidence-Based Counterterrorism Policy (pp. 65-88). New York: Springer.

Chappell, A. T. \& Gibson, S. (2009). Community policing and homeland security policing: Friend or foe?. Criminal Justice Policy Review, 20(3), 326-343.

Chermak, S., Carter, J. G., Carter, D. L., McGarrell, E. F. \& Drew, J. (2013). Law enforcement’s information sharing infrastructure: A national assessment. Police quarterly, 16(2), 211-244. Crank, J. P. \& Langworthy, R. (1992). An institutional perspective on policing. The Journal of Criminal Law and Criminology, 83(2), 338-363. 
Crank, J. P., Kadleck, C. \& Koski, C. M. (2010). The USA: the next big thing. Police Practice and Research, 11(5), 405-422.

Dabney, D. (2010). Observations regarding key operational realities in a Compstat model of policing. Justice Quarterly, 27(1), 28-51.

Darroch, S. \& Mazerolle, L. (2013). Intelligence-led policing: A comparative analysis of organizational factors influencing innovation uptake. Police Quarterly, 16(1), 3-37.

Deflem, M. (2008). Sociology of Law: Visions of a Scholarly Tradition. New York: Cambridge University Press.

DiMaggio, P. \& Powell, W. (1983). The iron cage revisited: Institutional isomorphism and collective rationality in organizational fields. American Sociological Review, 52(2), 147-160.

Eck, J. E. \& Spelman, W. (1993). Problem-solving: Problem-oriented policing in Newport News. In R. G. Dunham \& G. P. Alpert (Eds.) Critical Issues in Policing (pp. 451-466). Prospect Heights, IL: Waveland Press.

Edelman, L (1992). Legal ambiguity and symbolic structures: Organizational mediation of civil rights law. American Journal of Sociology, 97(6), 1531-1576.

Feeley, M. M. (1983). Court Reform on Trial. New York: Basic Books.

Global Intelligence Working Group. (2003), National Criminal Intelligence Sharing Plan. Washington, DC. Retrieved from http://www.it.ojp.gov/documents/National_Criminal_ Intelligence_Sharing_Plan.pdf.

Hallet, T. (2010). The myth incarnate: Recoupling processes, turmoil, and inhabited institutions in an urban elementary school. American Sociological Review, 75(1), 52-74.

Ingersoll, R. M. (1993). Loose coupled organizations revisited. Research in the Sociology of Organizations, 11(1), 81-112.

Innes, M. (2006). Policing uncertainty: countering terror through community intelligence and democratic policing. The ANNALS of the American Academy of Political and Social Science, 605(1), 222-241.

Lipsky, M. (1980). Street-Level Bureaucrats: Dilemmas of the Individual in Public Service. New York: Russell Sage Foundation.

Maguire, E. R. (1997). Structural changes in large municipal police organizations during the community policing era. Justice Quarterly, 14(3), 701-730. 
Maguire, E. R., Shin, Y., Zhao, J. \& Hassell, K. D. (2003). Structural change in large police agencies during the 1990s. Policing: An International Journal of Police Strategies and Management, 26(2), 251-275.

Mastrofski, S. K., Ritti, R. R., \& Hoffmaster, D. (1987). Organizational determinants of police discretion: The case of drinking-driving. Journal of Criminal Justice, 15(5), 387-402.

McGarrell, E., Freilich, J., \& Chermak, S. (2007). Intelligence-led policing as a framework for responding to terrorism. Journal of Contemporary Criminal Justice, 23(2), 142-158.

Meyer, J. W. \& Rowan, B. (1977). Institutionalized organizations: Formal structure as myth and ceremony. American Journal of Sociology, 83(2), 340-363.

Morabito, M. S. (2010). Understanding community policing as an innovation: Patterns of adoption. Crime and Delinquency, 56(4), 564-587.

Nakamura, R. T. \& Smallwood, F. (1980). The Politics of Policy Implementation. New York: St. Martin’s Press.

Orton, J. D. \& Weick, K.E. (1990). Loosely coupled systems: A reconceptualization. The Academy of Management Review, 15 (2), 203-223.

Phillips, S. W. (2008). Mandatory arrest: loosely coupled organizations, situational variables, and the arrest decision. International Journal of Police Science and Management, 10(4), 374387.

Phillips, S. W. (2012). Police supervisor's attitude toward analysis in policing: A force-field Analysis. IALEIA Journal, 21(1), 37-56.

Pressman, J. L. \& Waldavsky, A. B. (1984). Implementation: How Great Expectations in Washington are Dashed in Oakland. Berkeley: University of California Press.

Ratcliffe, J. H. (2008). Intelligence-led policing. Cullompton, UK: Willan Publishing.

Ratcliffe, J. \& Guidetti, R. (2008). State police investigative structure and the adoption of intelligence led policing. Policing: An International Journal of Police Strategies \& Management, 31(1), 109-128.

Randol, B. M. (2012). The organizational correlates of terrorism response preparedness in local police departments. Criminal Justice Policy Review, 23(3), 304-326.

Rosenbaum, D. (2002). Evaluating multi-agency anti-crime partnerships: Theory design, and measurement issues. Crime Prevention Studies, 4(1), 171-225. 
Schafer, J. A., Burruss, G. W., \& Giblin, M. J. (2009). Measuring homeland security innovation in small municipal agencies: Policing in a post-9/11 world. Police Quarterly, 12(3), 263-288.

Schaible, L. M. \& Sheffield, J. (2012). Intelligence-led policing and change in state law enforcement agencies. Policing: an international journal of police strategies and management, 35(4), 761-784.

Skogan, W. G. \& Hartnett, S. M. (2005). The diffusion of information technology in policing. Police Practice and Research, 6(5), 401-17.

Sherman, L. W., Milton, C. H. \& Kelly, T. V. (1973). Team Policing: Seven Case Studies. Washington DC: Police Foundation.

Shih, T. H. \& Fan, X. (2009). Comparing response rates in e-mail and paper surveys: a metaanalysis. Educational Research Review, 4(1), 26-40.

Simic, M., Johnston, L. G., Baros, S., Andjelkovic, V., Novotny, T. \& Rhodes, T. (2006). Exploring barriers to 'respondent driven sampling' in sex worker and drug injecting sex worker populations in Eastern Europe. Journal of urban health, 83(1), 6-15.

Stinchombe, A. (1997). On the virtues of old institutionalism. Annual Review of Sociology, 23(1), 1-18.

Stojkovic, S., Kalinich, D. \& Klofas, J. (2003). Criminal Justice Organizations: Administration and Management. ( ${ }^{\text {rd }}$ ed). Independence: Thomson.

Thompson, J. D. (1967). Organizations in action: Social science bases of administrative theory. New York: McGraw-Hill.

The Police Chief. (2003). The National Criminal Intelligence Sharing Plan, The Police Chief, International Association of Chiefs of Police, 70(11). Retrieved from http://www.policechiefmagazine.org/magazine/index.cfm?fuseaction=display_archandarticle _id=137andissue_id=112003.

U.S. Department of Homeland Security. (2007). Target Capabilities List: A Companion to the National Preparedness Guidelines. Washington, DC. Retrieved from http://www.fema.gov/pdf/government/training/tcl.pdf.

Weick, K. (1969). The Social Psychology of Organizing. Reading, MA: Addison-Wesley. Weick, K. (1976). Educational organizations as loosely coupled systems. Administrative Science Quarterly, 21(1), 1-19. 
Weick, K. (1982). Management of organizational change among loosely coupled elements. In P. Goodman (Ed.) Change in Organizations (pp. 375-408). San Francisco: Jossey-Bass.

Williams, W. (1982). Studying Implementation: Methodological and Administrative Issues. Chatham, NJ: Chatham House Publishers.

Wood, J. \& Shearing, C. (2007). Imagining Security. Devon, UK: Willan. 


\section{Tables}

Table 1. Respondent Demographics $(n=272)$

\begin{tabular}{ll}
\hline & N (Valid Percent) \\
\hline Agency Size & $35(13 \%)$ \\
10 or Less & $84(31 \%)$ \\
$11-99$ & $153(56 \%)$ \\
100 or more & $60(22 \%)$ \\
Agency Region & $62(23 \%)$ \\
Northeast & $73(27 \%)$ \\
Southeast & $30(11 \%)$ \\
Midwest & $47(17 \%)$ \\
Southwest & \\
West & $82(30 \%)$ \\
Respondent's Position & $62(23 \%)$ \\
Administrator & $87(32 \%)$ \\
Supervisor & $41(15 \%)$ \\
Investigator & \\
Analyst & $1(0.3 \%)$ \\
Respondent Years at Agency & $16(6 \%)$ \\
Less than 1 Year & $49(18 \%)$ \\
1-3 Years & $57(21 \%)$ \\
4-9 Years & $149(55 \%)$ \\
10-15 Years & \\
More than 15 Years &
\end{tabular}


Table 2. Descriptive Statistics $(n=272)$

\begin{tabular}{lcccc}
\hline Variable & Min & Max & Mean & S.D. \\
\hline Dependent & & & & \\
Analytic Products Scale & 7 & 35 & 16.73 & 7.12 \\
Information Sharing Rewarded & 0 & 1 & 0.40 & 0.49 \\
Relationships Scale & 6 & 24 & 18.41 & 3.57 \\
Provide Intelligence Scale & 6 & 24 & 13.80 & 4.81 \\
Receive Intelligence Scale & 6 & 24 & 14.13 & 4.48 \\
Intelligence Integrated Decision Making & 1 & 4 & 2.65 & 0.83 \\
& & & & \\
Independent & & & & \\
Follows NCISP & 1 & 4 & 2.40 & 0.86 \\
Align with TCL & 1 & 4 & 2.11 & 0.93 \\
Intelligence Policy & 0 & 2 & 1.09 & 0.88 \\
Information Sharing with Public & 0 & 1 & 0.44 & 0.50 \\
Sufficient Staff & 1 & 4 & 2.09 & 0.78 \\
All Crimes SARs & 0 & 1 & 0.75 & 0.43 \\
Federal Privacy Consistent & 0 & 1 & 0.51 & 0.50 \\
Audit Intelligence Records & 1 & 4 & 2.36 & 1.26 \\
Intelligence Training Required & 0 & 1 & 0.21 & 0.41 \\
Agency Size* & 5 & 50,688 & 1,322 & 3,720 \\
Agency Size (ln) & 0.69 & 10.83 & 5.75 & 1.83 \\
\hline
\end{tabular}

*The inclusion of the six largest U.S. municipal police agencies greatly skews the descriptive measures of agency size. The median agency size in the sample is 276. 
Table 3. Intelligence-Led Policing Behaviors Regressed on Agency Intelligence Characteristics $(n=272)$

\begin{tabular}{|c|c|c|c|c|c|c|c|c|c|}
\hline \multirow{2}{*}{ Variable } & \multicolumn{3}{|c|}{ Analytic Products Created } & \multicolumn{3}{|c|}{ Integrated Decision Making } & \multicolumn{3}{|c|}{ Information Sharing Rewarded } \\
\hline & $\operatorname{Exp}(B)$ & S.E. & $\mathrm{t}$ & $\operatorname{Exp}(B)$ & S.E. & $\mathrm{t}$ & O.R. & S.E. & $\mathrm{t}$ \\
\hline Follows NCISP & 1.004 & 0.001 & $4.81 * * *$ & 1.004 & 0.001 & $2.97 * *$ & 1.050 & 0.011 & $4.79 * * *$ \\
\hline Align with TCL & 1.066 & 0.034 & $1.99 *$ & 1.016 & 0.019 & 0.83 & 1.053 & 0.210 & 0.26 \\
\hline Intelligence Policy & 1.118 & 0.500 & $2.51 *$ & 1.042 & 0.030 & 1.42 & 1.378 & 0.490 & 0.90 \\
\hline Information Sharing with Public & 1.068 & 0.071 & 0.99 & 1.052 & 0.039 & 1.39 & 2.679 & 0.978 & $2.70^{* *}$ \\
\hline Sufficient Staff & 1.073 & 0.039 & 1.96 & 1.081 & 0.029 & $2.89 * *$ & 2.017 & 0.618 & $2.29 *$ \\
\hline All Crimes SARs & 0.991 & 0.064 & -0.15 & 1.035 & 0.038 & 0.94 & 0.881 & 0.385 & -0.29 \\
\hline Federal Privacy Consistent & 1.189 & 0.101 & $2.01^{*}$ & 1.065 & 0.051 & 1.31 & 0.755 & 0.404 & -0.53 \\
\hline Audit Intelligence Records & 0.992 & 0.033 & -0.22 & 0.996 & 0.024 & -0.16 & 0.670 & 0.133 & -1.89 \\
\hline Intelligence Training Required & 1.111 & 0.061 & 1.91 & 1.084 & 0.039 & $2.23^{*}$ & 3.274 & 1.308 & $2.97 * *$ \\
\hline Agency Size (ln) & 1.062 & 0.016 & $3.96 * * *$ & 1.010 & 0.010 & 0.95 & .824 & 0.108 & -1.48 \\
\hline
\end{tabular}

${ }^{*} p<.05,{ }^{* *} p<.01,{ }^{* * *} p<.001$ 
Table 4. Information Sharing Behaviors with External Agencies Regressed on Agency Intelligence Characteristics $(n=272)$

\begin{tabular}{|c|c|c|c|c|c|c|c|c|c|}
\hline \multirow{2}{*}{ Variable } & \multicolumn{3}{|c|}{ Relationships } & \multicolumn{3}{|c|}{ Provide Intelligence } & \multicolumn{3}{|c|}{ Receive Intelligence } \\
\hline & $\operatorname{Exp}(B)$ & S.E. & $\mathrm{t}$ & $\operatorname{Exp}(B)$ & S.E. & $\mathrm{t}$ & $\operatorname{Exp}(\mathrm{B})$ & S.E. & $\mathrm{t}$ \\
\hline Follows NCISP & 1.003 & 0.000 & $2.91 * *$ & 1.004 & 0.001 & $4.61 * * *$ & 1.005 & 0.001 & $5.39 * * *$ \\
\hline Align with TCL & 1.036 & 0.012 & $2.96 * *$ & 1.081 & 0.025 & $3.36 * * *$ & 1.061 & 0.031 & $2.01 *$ \\
\hline Intelligence Policy & 1.030 & 0.022 & 1.33 & 1.104 & 0.052 & $2.10 *$ & 1.071 & 0.059 & 1.23 \\
\hline Information Sharing with Public & 1.052 & 0.024 & $2.19 *$ & 1.015 & 0.052 & 0.28 & 0.994 & 0.056 & -0.10 \\
\hline Sufficient Staff & 0.989 & 0.013 & -0.80 & 0.987 & 0.029 & -0.44 & 0.970 & 0.026 & -1.13 \\
\hline All Crimes SARs & 0.988 & 0.023 & -0.52 & 0.985 & 0.051 & -0.29 & 1.032 & 0.055 & 0.59 \\
\hline Federal Privacy Consistent & 0.992 & 0.028 & -0.27 & 0.924 & 0.058 & -1.27 & 0.909 & 0.055 & -1.58 \\
\hline Audit Intelligence Records & 1.015 & 0.011 & 1.35 & 1.075 & 0.025 & $3.08 * *$ & 1.060 & 0.032 & 1.90 \\
\hline Intelligence Training Required & 1.004 & 0.022 & 0.19 & 1.095 & 0.049 & $2.04 *$ & 1.071 & 0.057 & 1.28 \\
\hline Agency Size (ln) & 1.021 & 0.001 & $2.90 * *$ & 1.037 & 0.012 & $3.05^{* *}$ & 1.032 & 0.017 & 1.87 \\
\hline
\end{tabular}

${ }^{*} p<.05,{ }^{* *} p<.01,{ }^{* * *} p<.001$ 


\section{Appendix A}

\section{Survey Items for Variables}

\section{Dependent Variables}

Intelligence Products Scale

Item: "How frequently does your agency create the following intelligence products?"

Bulletins

Risk Assessments

Advisories

Alerts

Warnings

Executive Reports

Briefings

Response options: “Never”, “Once or Twice a Year”, “Monthly”, “Weekly”, “Daily”

Alpha $=.908$

Factors analysis eigenvalue $=4.563$

Information Sharing Rewarded

Item: "Information sharing is explicitly rewarded in our organization (e.g. by formal evaluation)”

Response options: "Yes”, "No"

\section{Relationships Scale}

Item: "How close is the working relationship between your organization and the following agencies?”

FBI

Other Federal Law Enforcement Agencies

State Law Enforcement Agencies

Local Law Enforcement Agencies

Your State Fusion Center

Other State Fusion Center

Response options: "Very Close”, "Somewhat Close”, “Distant”, "We Have No Relationship"

Alpha $=.781$

Factors analysis eigenvalue $=2.935$ 
Provide Intelligence Scale

Item: "How often do your provide actionable intelligence to the following agencies?"

FBI

Other Law Enforcement

State Law Enforcement

Local Law Enforcement

State Fusion Center

Other State Fusion Center

Response options: "Very Frequently", "Frequently”, "Infrequently”, "Very Infrequently” Alpha $=.895$

Factors analysis eigenvalue $=3.966$

Receive Intelligence Scale

Item: "How often do you receive actionable intelligence from the following agencies?"

FBI

Other Law Enforcement

State Law Enforcement

Local Law Enforcement

State Fusion Center

Other State Fusion Center

Sheriffs

Response options: "Very Frequently”, "Frequently”, "Infrequently”, "Very Infrequently" Alpha $=.808$

Factors analysis eigenvalue $=3.137$

Intelligence Integrated Decision Making

Item: "How often is intelligence formally integrated into your agency's decision-making process"

Response options: “All the Time”, “Sometimes”, “Occasionally”, “Never”

\section{Independent Variables}

Follows NCISP

Item: "Does your agency's intelligence function follow the NCISP recommendations?"

Response options: "Completely”, "Mostly", "Some”, "Not at All”

Align with TCL

Item: "Does your agency's intelligence function align with the Department of Homeland Security Target Capabilities List?”

Response options: "Completely", "Mostly", "Some”, "Not at All” 


\section{Intelligence Policy}

Item: "Do you have a policy designed expressly to guide your intelligence function?"

Response options: "Yes", "Currently in Development", "No"

\section{Information Sharing with Public}

Item: "Our agency has processes in place for sharing relevant terrorism information with the public"

Response options: "Yes, "No"

\section{Sufficient Staff}

Item: "We have a sufficient number of staff to achieve our agency's intelligence capacity mission"

Response options: “Strongly Agree”, “Agree”, “Disagree”, Strongly Disagree”

\section{All Crimes SARs}

Item: "Are your Suspicious Activity Reports for all crimes?"

Response options: "Yes, "No"

\section{Federal Privacy Consistent}

Item: "Does your privacy policy meet the federal privacy policy standards?"

Response options: "Yes, "No"

Audit Intelligence Records

Item: "Do you audit your intelligence function and records?"

Response options: "Yes, Regularly”, "Yes, Occasionally”, "Yes, As Needed”, "No”

\section{Intelligence Training Required}

Item: "All personnel responsible for the intelligence function in the agency are required to receive specific training on ILP"

Response options: "Yes, "No"

\section{Agency Size}

Data was taken from the Federal Bureau of Investigation, Uniform Crime Report Police Employee Data. Agency size is the sum of sworn and non-sworn personnel.

\section{Author Bios}


Dr. Jeremy G. Carter is an assistant professor within the School of Public and Environmental Affairs at Indiana University - Purdue University Indianapolis and earned his Ph.D. from the School of Criminal Justice at Michigan State University. His research areas include policing, policy evaluation, justice technologies, law enforcement intelligence, and counter-terrorism. His research has appeared in outlets such as Police Quarterly, Criminal Justice and Behavior, Policing \& Society, Criminal Justice Policy Review, Journal of Crime and Justice, Police Practice and Research, Journal of Applied Security Research, and Law Enforcement Executive Form. Dr. Carter was recently confirmed as a lecturer at the Federal Bureau of Investigation's National Academy within the Advanced Intelligence Training Unit in Quantico, VA where he will instruct law enforcement leaders on intelligence-led policing.

Scott W. Phillips is an associate professor in the Criminal Justice Department at SUNY-Buffalo State. He earned a PhD from SUNY Albany and his research focuses on empirical examinations of police decision making, police attitudes, and police culture. His works have appeared in Journal of Criminal Justice, Police Research and Practice, Criminal Justice Policy Review, Policing: An International Journal of Police Strategies and Management, and the International Journal of Police Science and Management, Policing \& Society. Dr. Phillips has worked as the Futurist Scholar in Residence with the Behavioral Science Unit at the Federal Bureau of Investigation's National Academy in Quantico, VA.

S. Marlon Gayadeen is an assistant professor in the Criminal Justice Department at SUNY -Buffalo State. He earned his $\mathrm{PhD}$ in Sociology, from the University at Buffalo. His research interests are in criminology, deviance, deviant behavior and organizational sociology. His scholarship appears in Police Journal: Theory, Practice and Principles and the International Journal of Police Science \& Management. 